\title{
SMART PV GRID TO REINFORCE THE ELECTRICAL NETWORK
}

\author{
Mohamed Y. AL-Hamad \\ Power Trade Senior Executive \\ Market Operations \\ GCC Interconnection Authority \\ K. S. A. \\ mhamad@gccia.com.sa
}

\author{
Isa S. Qamber \\ Dept. Electrical \& Electronics Eng. \\ Professor of Electrical Eng. \& Energy \\ University of Bahrain, P. O. Box 32038 \\ Kingdom of Bahrain \\ iqamber@uob.edu.bh
}

\begin{abstract}
:
Photovoltaic (PV) became the new competitive energy resources of the planet and needs to be engaged in grid to break up the congestion in both Distribution and Transmission systems. The objective of this research is to reduce the load flow through the distribution and transmission equipment by $20 \%$. This reduction will help in relief networks loaded equipment's in all networks. Many projects are starting to develop in the GCC countries and need to be organized to achieve maximum benefits from involving the Renewable Energy Sources (RES) in the network.

The GCC countries have a good location for solar energy with high intensity of the solar radiation and clear sky along the year. The opportunities of the solar energy is to utilize and create a sustainable energy resource for this region.

Moreover, the target of this research is to engage the PV technology in such a way to lower the over loaded equipment and increases the electricity demand at the consumer's side.
\end{abstract}

\section{Keywords:}

Photovoltaic, Smart Grid, Peak load, Renewable energy, Energy Managements.

\section{Introduction:}

Over the last 10 years solar technology grew fast worldwide. The construction cost of the PV has dropped more than 70\%. The GCC countries' noon time peak load demand is the most expensive hours, which is recorded during the day during summer periods from 13:00hrs to 14:30 hrs. The cost during the system peak duration goes very high, interim of generation costs. Also, these hours are the most stressed hours for transmission and distribution systems which are used to give consumers the required power for these hours [1]. 
Bayindir and others [2] explore the need of transforming the power grid into a more reliable, secure, efficient and clean network. The authors mentioned that the Smart Grids (SGs) take a large step to develop the global power utilities industry [2]. At present time the new concept of SGs and the functional relationship between the different subsystems and technologies. The SGs help to utilize the involvement of new Renewable Energy Sources for the benefit of the customers by reducing the costs of operation and network reinforcements. The utility sectors of the GCC networks are not created like these markets, where the demand response and development of the smart customer sector could achieve the utilization of the new concepts partially.

More utilization could be achieved by introducing the Markets in GCC region as proposed by Al-Hamad and Qamber [3, 4]. They observed that all member states have the opportunity of power trading in a short-term contract market, such as monthly contracts. All member states have the opportunity for power trading in the spot market.

The present paper focuses solely on the use of PV system in the smart grid and shows its importance and utility. PV is used worldwide in many applications, from the major cities in the developed countries to primary rural villages in developing states. The PV system is illustrated as a means to generate electricity by utilizing directly from the sunlight. The PV is a cost-effective alternative in rural areas where extending a utility power line is very expensive. The PV has less operating cost and takes less maintenance, generate electricity without polluting the environment and without creating disturbance. The PV can be integrated into a grid with other types of generators [5]. These are considered as advantages of the PV.

Single PV/Solar cells are connected electrically to form PV modules. The solar cells can be connected in a certain way to power a wide kind of electrical equipment. The components taken to complete a PV system may include batteries, charge controller, inverter, dis-connectors or fuses, ground circuit and wiring.

Integrating PV into the residential areas will help develop Green Energy Market in GCC countries. The PV helps in putting back the formal facade, roofing materials and keeping off the cost of support structures. This organization is called the Building-Integrated PV (BIPV). These systems include crystalline modules integrated into roofing systems and practiced as 'eyebrows' over windows. As well, these systems practiced glass-on-glass modules used in skylights and view walls. 
In many applications, PV is used in Utility Systems including large centralized generation, transmission and distribution support including housing, commercial, and agricultural demand. In addition, in the more modern system, it is used in the Demand-side management (DSM).

DSM systems have a special value of energy between high demand and low demand, where high demand for the power present the most expensive period. Transmission and distribution support has a value because of the need of more infrastructure and investment to transfer the energy, where utilities can install a PV near to overloaded equipment to eliminate or delay the need for costly upgrades.

\section{Renewable Energy Targets of GCC Countries:}

GCC country's renewable energy targets illustrated in Table (1), presents decent renewable energy targets. The targets [6] varied from 5\% to $20 \%$ until 2030.

Table (1) Renewable Energy Targets of GCC Countries

\begin{tabular}{|c|c|c|}
\hline GCC State & $\begin{array}{c}\text { Target of Renewable } \\
\text { Energy }\end{array}$ & Year \\
\hline Bahrain & $5 \%$ of the Capacity & 2020 \\
\hline Kuwait & $5 \%$ of Generation & 2020 \\
\hline Kuwait & $15 \%$ of Generation & 2030 \\
\hline Oman & $10 \%$ of Generation & 2020 \\
\hline Qatar & $20 \%$ of the Capacity & 2030 \\
\hline $\begin{array}{c}\text { Saudi } \\
\text { Arabia }\end{array}$ & 9.5 GW & 2020 \\
\hline $\begin{array}{c}\text { Saudi } \\
\text { Arabia }\end{array}$ & 54 GW & 2040 \\
\hline Abu Dhabi & $7 \%$ of Capacity & 2020 \\
\hline
\end{tabular}




\begin{tabular}{|c|c|c|}
\hline Dubai & 5 GW of Capacity & 2030 \\
\hline
\end{tabular}

The average target is 5\% of the member state's consumption, where the growth of consumption assumed at 5\% per annum. The requirement of the renewable energy is around 34,180 GWh for GCC States for the year 2020. Considering the deployment of solar energy to meet the 5\% renewable energy target would mean installing a deployment of active production from Renewable Energy Sources in GCC countries around 20,000 MW by the year 2020 .

\section{Retail Electricity Prices:}

The electricity prices in the GCC countries have always been a subject of debate due to the subsidies at upstream level and hence cannot be exactly quantified. While the GCC states are actively working on having a cost reflective tariffs in place, the existing average retail electricity tariffs as presented in Table (2).

Table (2) Average Retail Electricity Tariffs in GCC

\begin{tabular}{|c|c|c|c|}
\hline \multicolumn{4}{|c|}{ Retail Electricity Tariff in US $\varnothing / \mathrm{kWh}$} \\
\hline GCC State & Residential & Commercial & Industrial \\
\hline Bahrain* [7] & 4.11 & 5.17 & 5.98 \\
\hline Kuwait* [8] & 3.87 & 8.30 & 3.32 \\
\hline Oman [9] & 3.25 & 5.19 & 4.16 \\
\hline Qatar [10] & 2.38 & 3.20 & 4.12 \\
\hline Saudi Arabia [11] & 2.22 & 5.69 & 4.80 \\
\hline UAE [12] & 8.36 & 4.36 & 4.99 \\
\hline
\end{tabular}

*Proposed Tariffs for 2017

\section{PV Unit Components:}


The main PV system components are Solar Cells Array, Charge Controller, Battery, DC-DC converter, DC-AC inverter, and AC load connected to electrical power grid are presented in [13].

A Charge Controller is used to govern the flow of electricity from the PV modules to the battery as well as both DC-DC converter and DC-AC inverter. It keeps the battery fully charged without overcharging it. Then, when the controller senses that the battery is fully loaded, it breaks the flow of direction from the PV modules. The controller allows charge to flow from the modules into battery, the load or both when the load is getting power.

The battery is used to charge/discharge the electricity, which will be utilized at nighttime or when the modules are not generating sufficient power to meet load demand. Deep-cycle batteries are utilized in this scheme [14]. Depth of discharge in conjunction with battery capacity is a fundamental parameter in the design of battery bank of PV system and the effect of their multiplication represents the energy which can be pulled from a shelling. A deep-cycle battery is designed to gradually discharge and recharge up to $80 \%$ of their capacity hundreds of times. The shallow - cycle battery should not be used in PV system because it can discharge only $20 \%$ of their capacity. Thus, if extracting much more of its capacity and for several times, the battery will be damaged and no longer be able to hold a commission. In order to reach the same usable capacity, a shallow-cycle battery must have a larger capacity than a deep-cycle battery. PV systems may accept to be sized to lay in sufficient batteries to meet energy during the night.

The Inverter also may be used in PV system to convert the DC electricity produced by PV modules or batteries into AC electricity. The Inverter cost is affected by various factors such as, the quality of electricity it needs to grow, the incoming DC voltage, the load required, the amount of extra surge power the $\mathrm{AC}$ loads need for little periods and whether the inverter has any extra features like meters and indicator lights.

\section{PV Array Arrangement:}

With respect to the PV Array Arrangement there are three systems for connecting PV arrays, which are series connection, parallel connection and combination of series \& parallel connection. The voltage for the PV module in series connection is 
additive while the current/ampere stays the same. The voltage stays the same in the parallel connection where the current is additive.

Normally, One PV panel available in the market generates 200W. The PV array arrangement proposed is a combination of $8 \times 7$ panels. The array combination will generate $11200 \mathrm{~W}$. The power factor of the electrical load connected in the main electrical network in the Kingdom of Bahrain is 0.85. The apparent power for the PV array proposed for 0.85 power factor is $13.167 \mathrm{kVA}$ [15].

The inverter and charging/discharging of battery efficiency is found to be close to $80 \%$ [14]. Counting the losses of inverter and battery efficiency, the total power transferred to the grid is $10.54 \mathrm{kVA}$.

\section{PV Array in Electricity Distribution System:}

The modern electricity distribution system starts from the principal sub-station and reaches by the secondary service enter the customer's meter socket. It conducts electricity from the transmission organization and presents it to consumers.

This paper proposes to use PV system in the city network. In the Gulf region domestic load increases in summer time due to wide usage of air-conditioners. City network requires reinforcement due to increase of domestic cargo. Increase in load becomes a critical issue if the substation transformer increases more than $80 \%$ of its capacity and ambient temperature more than $40^{\circ} \mathrm{C}[15]$.

The transformer load ability versus ambient temperature is shown in Fig (1), which is established in the IEEE standard $[13,16]$. The normal lifetime of the transformer (meaning normal solid insulation life) is 180,000 hours or 20.6 years are based on continuous operation at a design hotspot temperature of $110^{\circ} \mathrm{C}$. 


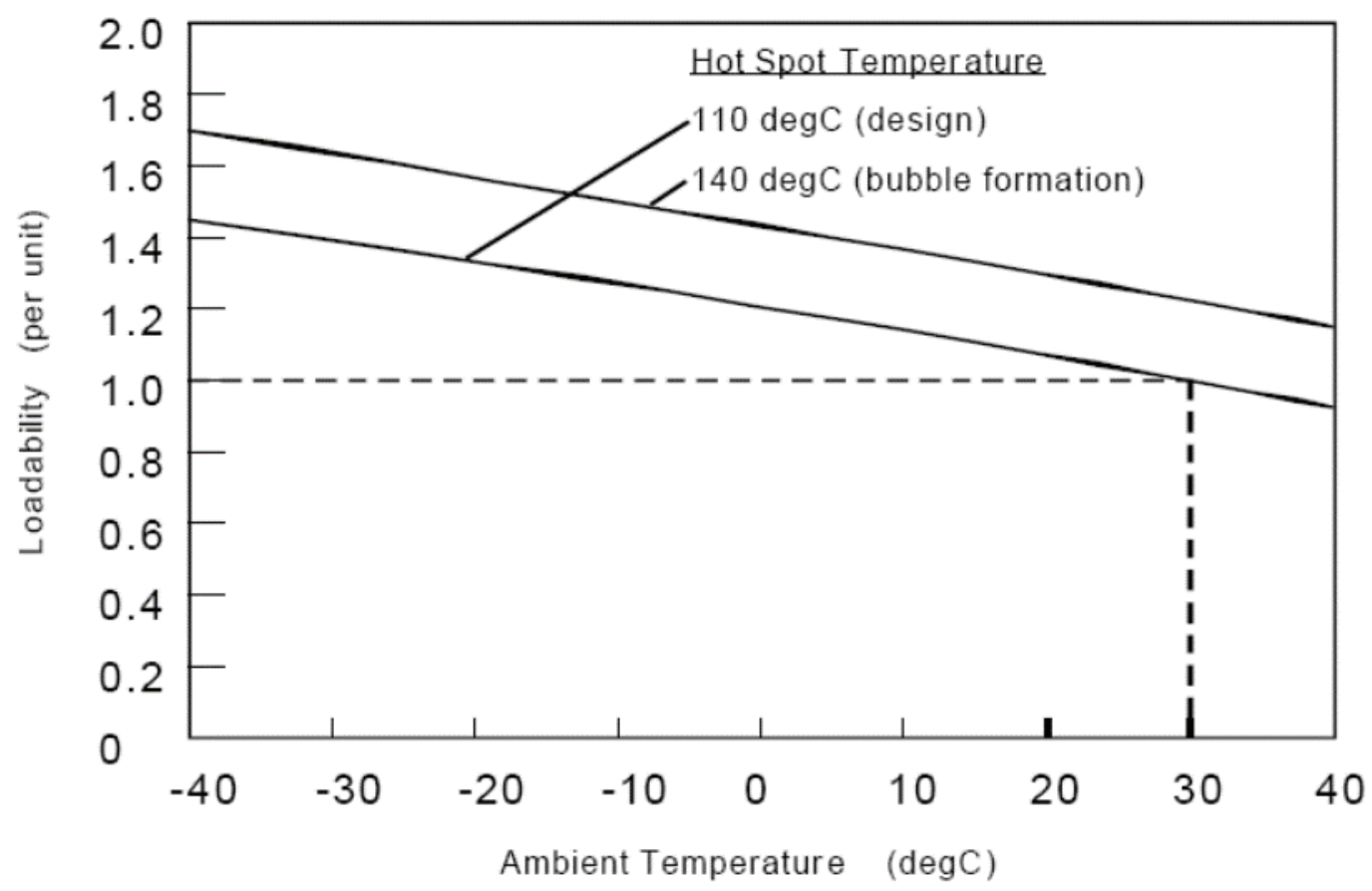

Fig (1) Transformer load ability versus ambient temperature

Table (3) shows nonlinear formula relating the rate of loss of life, which increased with an addition in the 'hot spot' temperature. Hot spot temperature is shown by the 'winding temperature' gauge. When the ambient temperature reaches $45^{\circ} \mathrm{C}$ and the transformer capacity reaches a full rate, the loss of life estimated will reach 16 times of normal loss life.

It should be noted that the operation at the 'oil bubbles' condition is taken for a short period of time as the bubbles re-fade out when the oil cools.

In the Kingdom of Bahrain ambient temperature in summer rises normally over $40^{\circ} \mathrm{C}$, and reaches $45^{\circ} \mathrm{C}$ in July and August. Therefore, transformer loading should not be more than $80 \%$ based on the IEEE standard to avoid loss of life [16].

Table (3) Rate of loss of life to other values of hot spot temperature

\begin{tabular}{l|lll}
\hline $\begin{array}{l}\text { Hot Spot Temperature Rate of Loss of } \\
\text { Life }\left({ }^{\circ} \mathrm{C}\right)\end{array}$ & $\begin{array}{l}\text { degrees Celsius relative to } \\
\text { normal }\left({ }^{\circ} \mathrm{C}\right)\end{array}$ \\
\hline $110($ design value) & 1 & & \\
117 & 2 & & \\
124 & 4 & \\
\hline
\end{tabular}




\begin{tabular}{l|l}
\hline 131 & 8 \\
139 (oil bubbles) & 16 \\
147 & 32 \\
\hline
\end{tabular}

\section{Reinforcement of Network Results:}

The medium-voltage (MV) of electricity distribution system consists of many rings connected between different MV bus bars. Each ring contains a number of substations, which transfer the power from MV to the Low Voltage (LV). The ring load accepted for the Kingdom of Bahrain is 6MVA. Number of substations connected at the ring on average are 10 substations. On average, a substation has 5 or 7 Low Voltage feeders supplying the homes. Normally one feeder is supplying 5 homes.

Average number of houses connected to one substation of capacity $1500 \mathrm{kVA}, 1000$ kVA and $500 \mathrm{kVA}$ are 30, 20 and 10 houses, respectively. If each house has PV unit, total load generated by the PV array for different types of substation will be 316 $\mathrm{kVA}, 211 \mathrm{kVA}$ and $105 \mathrm{kVA}$, respectively. The load generated by the PV array as compared to the capacity of the transformer of distribution substation is equal to $21 \%$. This measure of load generated is equivalent of a load required to relieve transformers from the $100 \%$ loading to the $80 \%$ loading level.

This technique can be applied to avoid reinforcement of the Low voltage feeder, whose loading exceeds $80 \%$ of its LV feeder capacity. Likewise, the $11 \mathrm{kV}$ feeder will be reinforced by the same measure of loading, which is $21 \%$ of the current burden. All equipment's in the transmission side will be also relieved by $20 \%$. The Power generated by power station will be cut by $21 \%$.

Impact of renewable energy on the tariffs as per our study, considering the international fuel prices, the generation costs in GCC countries for new power plants are in the range of US $\phi 4.2$ to US $\phi 15 / \mathrm{kWh}$ considering long-term, short-term and peak scenarios. The range of prices calculated for conventional power along with the solar tariffs discovered through a transparent bidding process in GCC States is illustrated in Fig (2). 


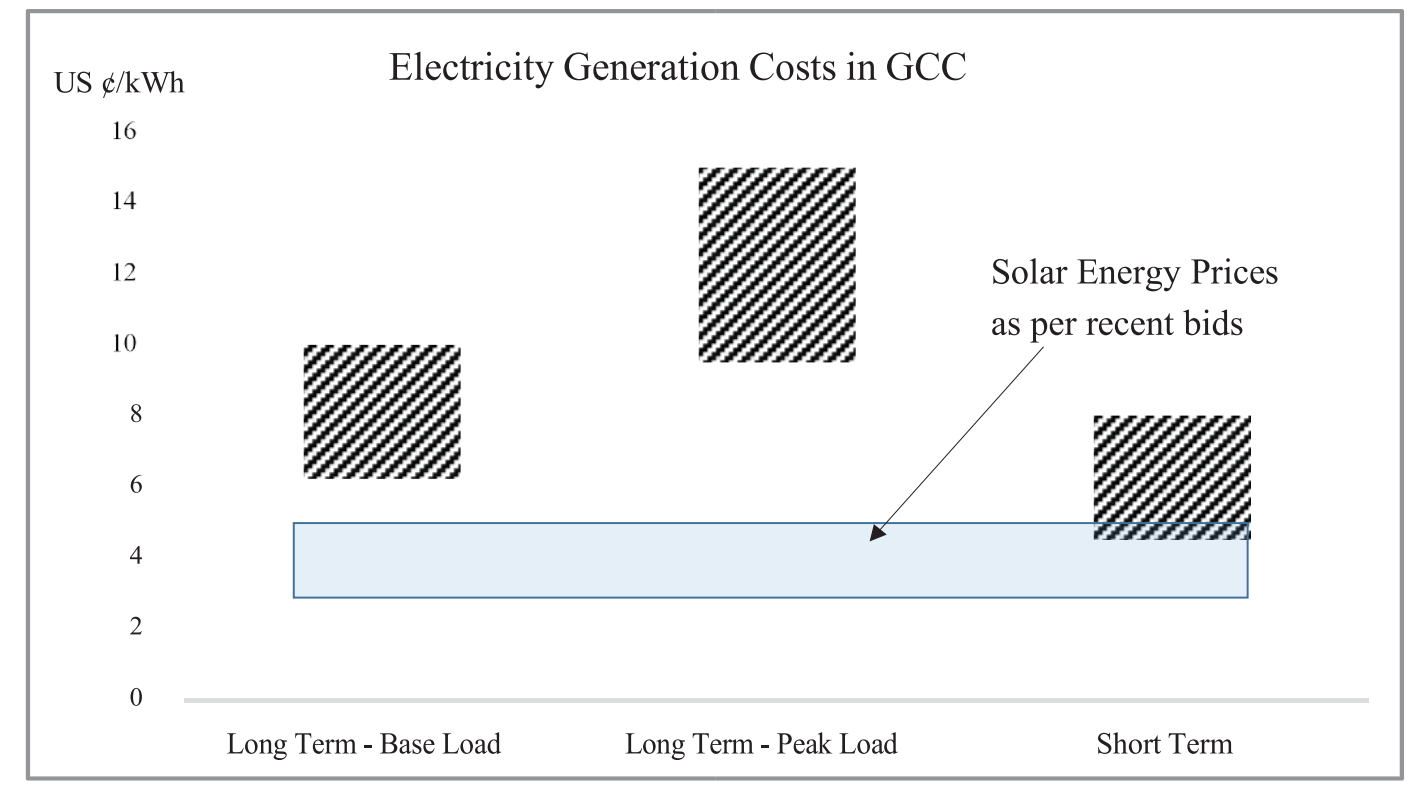

Fig (2) Electricity Generation Cost \& Solar Prices

\section{Impact of Solar Prices on Retail Tariff in GCC:}

While the generation costs of conventional power plants are more than USD 0.0242 per $\mathrm{kWh}$, the average realization is less than that. However, the tariffs of solar energy projects in the recent bids appear to be closer [17] to the retail tariffs of the GCC States.

It can be seen from Fig (2) that the solar tariffs are already proving to be more economical than the conventional sources of power generation.

Considering the conservative solar tariff of USD 0.0242 per kWh [17], which was the highest tariff in the most recent tariff based bid for the solar power project. The increase in average retail tariff of the GCC states for a share of 5\% of solar energy is presented in Fig (3). 


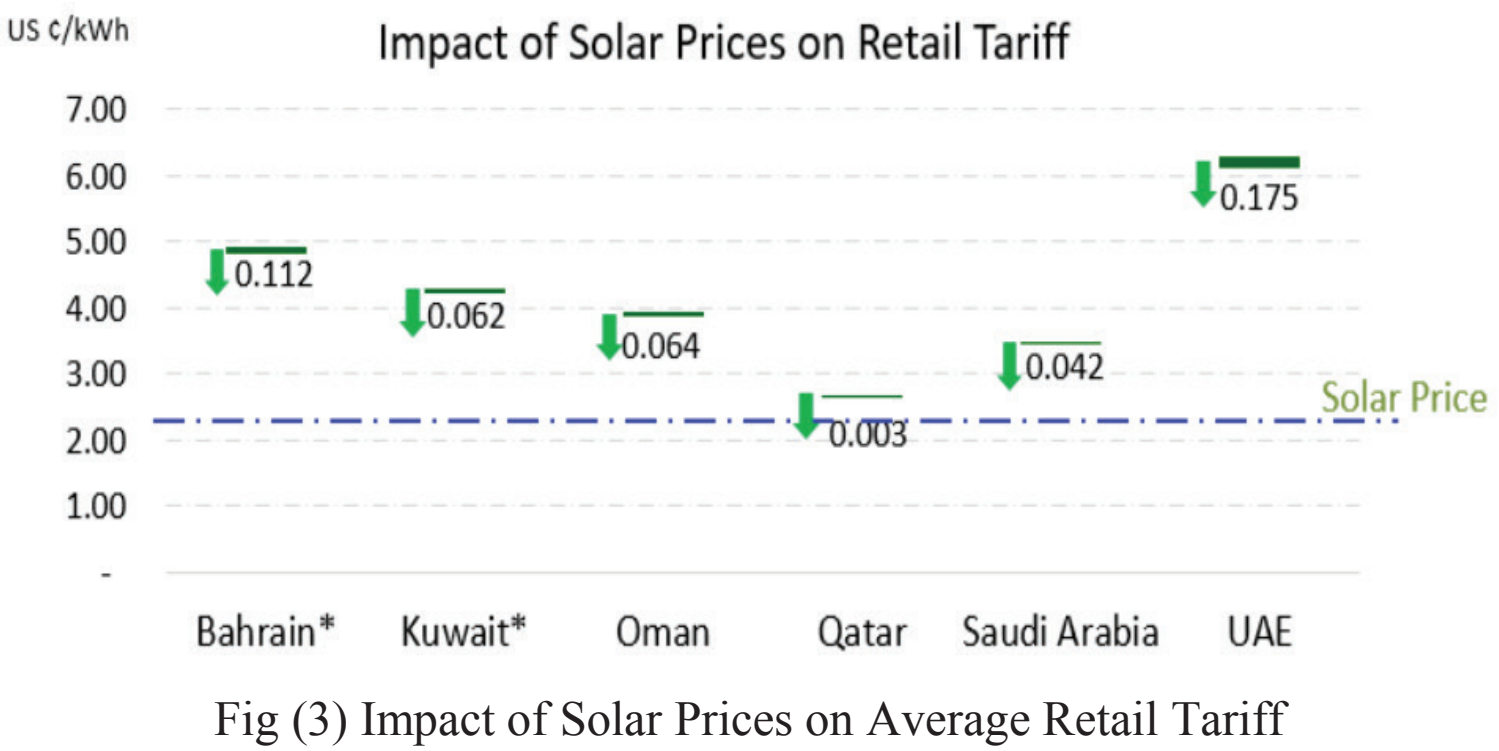

Fig (3) demonstrates that while there is a marginal increase in average retail electricity tariff due to the addition of 5\% solar energy, all member states have a reduction in average retail tariff. This will justify adding Renewable Energy Sources generation to the electricity utility industry.

\section{Innovative policies and regulations that can be introduced at national level of renewable energy:}

Some of the established policies for promotion of renewable energy for retail sale are wheeling of energy, banking, energy, renewable energy certificates and virtual power purchase agreements (PPA). Wheeling and banking policies have been carried out in many states.

Wheeling is the transfer of electric energy through transmission and distribution lines from the generator to the consumer. The same generated energy may not reach the consumer, but the electricity is passed to the consumer through energy displacement process.

For promotion of renewable energy, this wheeling (transmission) process needs to be simplified to the renewable energy generator and the consumer for scheduling. The existing base will hold good for the consumer to claim total or partial zip from 
the renewable energy generated with small or no modifications to the existing metering infrastructure of the consumer.

Oftentimes, the highest-quality renewable resources are situated far from major electricity load centers and in those cases, wheeling polices can support transmission to deliver renewable generation to those load centers.

Suggested types of polices are as follows:

a) Wheeling Policy for wheeling of electricity. Wheeling needs to be digested by the trading parties in addition to the wheeling charge the distribution network for the transmission \& the distribution network of the consumer and distribution network of the consumer. For the above computation, the wheeling charges for withdrawal of energy by the member nations have not been taken due to unavailability of data. Nevertheless, it should be mentioned that as a share of wheeling incentives for the renewable energy, the wheeling charges should be waived off by the member states to realize the scheme (renewable energy wheeling) more viable and attractive for the consumers. The utilities may also put up rebates on the transmission and distribution loss.

b) Banking/Metering Policy - Member State host the project should allow the banking \& metering facility for the renewable energy generated which can be scheduled for consumption later by the consumer. The modes and terms \& conditions for banking and metering of energy may be discussed with all the member states for agreeing terms.

c) Exchange Renewable Energy Sources with GCCIA - The energy may also be allowed to be exchanged through GCCIA with the member states in an agreed percentage with each member state.

d) Regional Renewable Energy Certificates - The Regional Renewable Energy Certificates system may as well be implemented at the GCC regional level. Nevertheless, the concept of wheeling and banking of energy will involve all the stakeholders in the growth of renewable energy in the area.

\section{Conclusion:}


The Smart Grid could help GCC countries in addressing the high load and stress on the electricity network. The Photovoltaic systems could be used to add electricity generation units in the city, areas where there is no space for PV arrays. The house's roof can be used to install the PV units to handle a portion of local demand. Millions of dollars are spent annually in the GCC countries to support the network, which can be utilized in building the PV smart grid in residential areas and to satisfy the aim of the reinforcement issue.

The proposed scheme will encompass the following advantages:

i) Relieves the distribution network, transmission network and force generated by approximately $5 \%$ to $20 \%$ by the year 2030 .

ii) All States will achieve their renewable energy targets, and allows the grid system to become more interoperable at a continual level to heighten protection and cost effectiveness "Smart grid".

iii) With subsidies being reduced, the average retail tariffs are now close to the solar generation tariffs.

iv) Cuts the cost of generation, transmission and distribution of electricity throughout the grid.

The present study recommendation is to make the investment in developing the GCC Smart Grid in smart way by utilizing the budget reduction expected from reinforcement schemes to build new PV system in the residential areas and create the Smart Grid in the GCC region. 


\section{References:}

1. M. Y. Al-Hamad, A. A. Al-Ebrahim, I. S. Qamber, "Opportunities for Power Trading through Diversity of Annual Maximum Load for GCC Countries”, GCC Cigre 2013 Conference \& Exhibition, Abu Dhabi, 18-20 November 2013.

2. R. Bayindir, I. Colak, G. Fulli, and K. Demirtas "Smart grid technologies and applications", Renewable and Sustainable Energy Reviews, Volume 66, December 2016, Pages 499-516.

3. M. Y. Al-Hamad, I. S. Qamber, “Activating GCC Power Market: Developing the Power Market and Involving the Electric Utilities", Paper No. A085, Cigre GCC Power 2014, 10 12 November 2014, Manama, Kingdom of Bahrain.

4. Isa S. Qamber, Mohammed Y. Al-Hamad, "Trading Opportunities Forecasted Benefits at Peak Load for GCC Countries", Electric Power and Water Desalination Conference, 2223 February 2016, Doha, Qatar.

5. M. AL-Hamad "Maximum Power Transfer from Photovoltaic Power Cell to Drive three Phases Induction Motors", University of Bahrain, Master thesis, 2005.

6. Renewable Energy Market Analysis, the GCC Region, IRENA - 2016.

7. Electricity and Water Authority. Tariff and charges rates collected in May 2016, Retrieved from http://www.mew.gov.bh/default.asp?

8. Energy Bill Increase to Hike Rents, Prices. Article retrieved from http://news.kuwaittimes.net /website/energy-bill-increase-hike-rents-prices/

9. My e-Portal, Tariff - MEDC collected in May 2016, Retrieved from http://www.electricity. com.om/tabid/178/Default.aspx

10. Qatar General Electricity \& Water Corporation, Retrieved from http://www.km.com.qa/ customerservice/pages/tariff.aspx

11. Electricity \& Co-Generation Regulatory Authority, Retrieved from www.ecra.gov.sa.

12. RSB Notification accessed from ADDC website, Retrieved from http://www.addc.ae/images/New\%20Tariff\%20Structure.pdf

13. Mohamed Y. AL-Hamad and Qahtan Hassan A.Alfaris, "Smart PV Grid to Reinforce the Electrical Network", Jordan Cigre National Committee (JCNC), 9-11 November 2010, Alzarqa, Kingdom of Jordan.

14. Battery Company: Northern Arizona Wind \& Sun, 4091 East Huntington Drive, Suite B, Flagstaff, AZ 86004, http://www.windsun.com/Batteries/Battery FAQ.htm.

15. Mohamed Y. AL-Hamad "Managing Transformers \& Feeders During Minor Overloading In Primary Substations to Avoid Load Shedding”, POWER-GEN Middle East 2008, 17th February 2009, Bahrain International Exhibition Centre.

16. Dick DeBlasio "IEEE P2030 Smart Grid Interoperability Standards Development KickOff Meeting Hosted by INTEL Corporation”, Santa Clara, California, June 3-5, 2009.

17. Sam Pothecary, Abu Dhabi: Three world record bids entered for Sweihan solar project, PC Magazine, 20th September 2016, Article, Retrieved from http://www.pvmagazine.com/news/details/beitrag/abu-dhabi--three-world-record-bids-entered-forsweihan-solar-project_100026191/\#ixzz4RChVGe23 